\title{
Changes in NSE and S-100 $\beta$ during the perioperative period and effects on brain injury in infants with biliary atresia undergoing parent donor liver transplantation
}

\author{
HONGLI YU, WENLI YU, MIN ZHU, GUICHENG ZHANG, YIWEI SHI and YING SUN \\ Department of Anesthesiology, Tianjin First Center Hospital, Tianjin 300192, P.R. China
}

Received February 22, 2020; Accepted July 23, 2020

DOI: $10.3892 /$ etm.2021.10156

\begin{abstract}
The present study aimed to investigate the effects of parental donor liver transplantation on the perioperative changes of serum calcium-binding protein $\beta$ (S-100 $\beta)$ and neuron-specific enolase (NSE) levels, two markers of brain injury, and on postoperative cognitive function. The present study was a prospective observational study of infants with congenital biliary atresia who underwent selective liver transplantation in 2017 at Tianjin First Central Hospital (Tianjin, China). Blood samples were collected prior to, during and following surgery, and S-100 $\beta$ and NSE levels were measured using ELISA. The pediatric patients were assessed using the Bayley Scales of Infant Development 1 day prior to and 3 months after surgery. Additionally, the pediatric anesthesia emergence delirium scores were evaluated. The results demonstrated that serum NSE and S100 $\beta$ were increased during and after surgery compared with prior to surgery $(\mathrm{P}<0.05)$. Furthermore, serum S-100 $\beta$ and NSE levels peaked $1 \mathrm{~h}$ after the neohepatic phase compared with prior to surgery $(\mathrm{P}<0.05)$. Compared with 1 day before surgery, mental development index (MDI) and psychomotor development index (PDI) were decreased 3 months after surgery (MDI, $87.7 \pm 8.4$ vs. $84.5 \pm 8.5, \mathrm{P}=0.015$; $\mathrm{PDI}, 82.9 \pm 8.7$ vs. $79.6 \pm 8.8$, $\mathrm{P}=0.016)$. In conclusion, parental donor liver transplantation may cause a certain degree of brain injury in pediatric patients with end-stage liver disease, as revealed by increased serum NSE and S100 $\beta$ levels.
\end{abstract}

\section{Introduction}

End-stage liver disease (ESLD) is caused by hepatic injury and leads to an irreversible loss of liver function, and changes in liver architecture and blood supply (1). The presenting

Correspondence to: Dr Wenli Yu, Department of Anesthesiology, Tianjin First Center Hospital, 24 Fukang Road, Nankai, Tianjin 300192, P.R. China

E-mail: yuhongli1126@foxmail.com

Key words: S100 calcium-binding protein $\beta$, neuron-specific enolase, liver transplantation, infant, brain injury symptoms vary widely from impaired synthesis of blood proteins to the loss of glucose or ammonia control and impaired bile acid production (1). While the incidence of ESLD in the pediatric population is low, the condition is severe and requires tertiary care $(1,2)$. Biliary atresia was the most common cause of pediatric ESLD in 2001 in Canada and the USA (43.4\%), followed by fulminant liver failure $(15.0 \%)$, cirrhosis $(9.1 \%)$ and metabolic diseases (8.0\%) (3). Liver transplant is the only curative treatment in numerous cases (4).

Parental donor liver transplantation has become the most effective treatment for pediatric patients with ESLD (5), with a worldwide postoperative 5-year survival rate of 70-90\% in 2011 (6,7). Although marked survival rate, complications after liver transplantation still occur (8). The incidence of neurological complications can be $20 \%$, which severely affects postoperative survival rates compared to those without (50 vs. 7\%) (9). The optimal timeframe for pediatric liver transplantation coincides with the peak time of cerebral development in children $(10,11)$. Therefore, pediatric patients undergoing transplantation during this period are at high risk of neurological complications, imposing challenges to the anesthesiologist for the protection of nervous system function and the reduction of neurological damage during the perioperative period.

Currently, anesthetic drugs and surgical trauma have the potential to cause the death of developing neurons, causing long-term injury to nerve function (12-15). S100 calcium-binding protein $\beta$ (S-100 $\beta$ ) is expressed by astrocytes and neuron-specific enolase (NSE) is expressed by ganglia cells $(16,17)$. S-100 $\beta$ is secreted by astrocytes and can be leaked into the circulation by injured astrocytes; blood levels of $S-100 \beta$ have been reported to be increased during the acute phase of brain damage (18-20). Similarly, leakage of NSE into the circulation indicates injured ganglia cells $(21,22)$. A meta-analysis revealed that NSE had a moderate predictive value for brain injury in pediatric patients (23). High postoperative levels of S-100 $\beta$ and NSE are associated with brain injury in pediatric patients who have undergone major surgeries $(24,25)$. However, to the best of our knowledge, perioperative changes in the levels of S-100 $\beta$ and NSE in pediatric patients with ESLD undergoing parental donor liver transplantation remain unknown.

Therefore, the present study investigated the effects of parental donor liver transplantation on the changes of serum 
NSE and S-100 $\beta$ during the perioperative period, on brain injury and on postoperative cognitive function. The results may aid in improving perioperative management in these pediatric patients.

\section{Materials and methods}

Study design and patients. The present prospective observational study investigated infants with congenital biliary atresia who underwent selective liver transplantation between January and December 2017 at Tianjin First Central Hospital (Tianjin, China). The present study was approved by the Medical Ethics Committee of Tianjin First Central Hospital (approval no. 2016N0039KY) and written informed consent was obtained from the infants' parents. The privacy rights of human patients were observed.

The inclusion criteria were as follows: i) 4-12 months of age; ii) an American Society of Anesthesiologists physical status of III or IV (26); and iii) scheduled to undergo elective pediatric living related donor liver transplantation. The exclusion criteria were: i) known or suspected allergies to propofol, soy and/or egg; ii) congenital heart disease, or impairment of renal or pulmonary function prior to liver transplantation; or iii) treatment with any other type of operation. All living donors were parents (father or mother). Every transplantation case received ethical review and approval from Tianjin First Center Hospital.

Anesthesia and intraoperative management. All infants underwent combined intravenous and inhalation anesthesia. Preoperatively, routine fasting was performed (formula and milk were not provided for $6 \mathrm{~h}$, breast milk for $4 \mathrm{~h}$ and water or sugary drinks for $2 \mathrm{~h}$ prior to surgery). Atropine $(0.01 \mathrm{mg} / \mathrm{kg})$ was intramuscularly injected $30 \mathrm{~min}$ prior to anesthesia. After being transferred to the operating room, routine monitoring of pulse oxygen saturation $\left(\mathrm{SpO}_{2}\right)$ and electrocardiograms were conducted. Peripheral venous access was opened. Rapid induction of anesthesia was performed using the following: $1 \mathrm{mg} / \mathrm{kg}$ methylprednisolone, $0.05 \mathrm{mg} / \mathrm{kg}$ midazolam, $0.2 \mathrm{mg} / \mathrm{kg}$ etomidate, $2 \mu \mathrm{g} / \mathrm{kg}$ fentanyl and $0.08 \mathrm{mg} / \mathrm{kg}$ vecuronium bromide. Auscultation of both lungs was performed following oral tracheal intubation to ensure clear breathing sounds in both lungs. The ventilator was connected to mechanical ventilation to observe the normal waveform of patient end-tidal carbon dioxide $\left(\mathrm{PETCO}_{2}\right)$. The fraction of inspired oxygen was $50-60 \%(100 \%$ at the anhepatic phase), tidal volume was $8-10 \mathrm{ml} / \mathrm{kg}$, respiratory rate was $20-26$ breaths $/ \mathrm{min}$ and the inspiration and expiration ratio was 1.0:1.5-2.0. A $\mathrm{PETCO}_{2}$ partial pressure of $30-35 \mathrm{mmHg}$ and airway pressure of $18-25 \mathrm{cmH}_{2} \mathrm{O}\left(1 \mathrm{~cm} \mathrm{H}_{2} \mathrm{O}=0.098 \mathrm{kPa}\right)$ was maintained. Following induction of stable anesthesia, bispectral index (BIS) values were monitored. B-mode ultrasound-guided radial artery catheterization for invasive blood pressure monitoring, and placement of a triple-lumen central venous catheter through the right internal jugular vein for monitoring of central venous pressure (CVP) and intraoperative infusion were performed. Anesthesia maintenance was performed using the following: Continuous intravenous infusion of $1 \%$ propofol at $9-15 \mathrm{mg} / \mathrm{kg} / \mathrm{h}, 0.1-0.2 \mu \mathrm{g} / \mathrm{kg} / \mathrm{min}$ remifentanil and $0.12 \mathrm{mg} / \mathrm{kg} / \mathrm{h}$ cisatracurium besylate. Additionally,
1-3 $\mu \mathrm{g} / \mathrm{kg}$ fentanyl was administered intermittently to maintain the depth of anesthesia. The intraoperative fluid infusion was warmed. Sodium lactate, glucose and albumin solution were intravenously infused. Body temperature was maintained at $35.5-37.5^{\circ} \mathrm{C}$. According to the results of intraoperative blood gas analysis and coagulation function monitoring, the appropriate amount of concentrated red blood cells and fresh frozen plasma were infused. By adjusting the transfusion speed and continuous intravenous infusion of small doses of dopamine, a mean arterial pressure (MAP) of $40-65 \mathrm{mmHg}$ $(1 \mathrm{mmHg}=0.133 \mathrm{kPa})$, a CVP of 6-8 $\mathrm{mmHg}$, a heart rate (HR) of 110-170 beats $/ \mathrm{min}$, a $\mathrm{SpO}_{2}$ of $95-100 \%$, a body temperature of $35.5-37.5^{\circ} \mathrm{C}$, a BIS of $40-60$, a $\mathrm{PETCO}_{2}$ of $35-45 \mathrm{mmHg}$, hemoglobin $>80 \mathrm{~g} / \mathrm{l}$ and a urine volume $>1 \mathrm{ml} / \mathrm{kg} / \mathrm{h}$ were maintained. According to the results of arterial blood gas analysis, the breathing parameters were adjusted throughout the surgery. A heating blanket and infusion heating device were used to maintain constant body temperature.

Data collection and examination methods. A total of $1 \mathrm{ml}$ central venous blood was collected into coagulation tubes a following anesthesia (T1), $30 \mathrm{~min}$ after the anhepatic phase (T2), and $1 \mathrm{~h}$ (T3) and $24 \mathrm{~h}$ (T4) after the neohepatic phase. The samples were placed at $37^{\circ} \mathrm{C}$ for $10 \mathrm{~min}$, centrifuged at $3,960 \mathrm{xg}$ $\mathrm{rpm}, 22-24^{\circ} \mathrm{C}$ for $10 \mathrm{~min}$ and stored at $-80^{\circ} \mathrm{C}$. NSE and S-100 $\beta$ were detected using ELISA kits (cat. nos. E01N0025 and S100 E01S0042, respectively; Shanghai Lanji Biotechnology Co., Ltd.). HR, MAP, CVP and BIS were recorded at each time point (T1-T4).

Two doctors independently conducted evaluations 1 day prior to surgery and 3 months after surgery. Pediatric end-stage liver disease model (PELD) score was calculated as follows: PELD Score $=[0.436 \mathrm{x}$ (age $<1$ year) $]-0.687 \mathrm{x} \log [$ albumin $(\mathrm{g} / \mathrm{dl})]$ $+0.480 \mathrm{x} \log$ [total bilirubin $(\mathrm{mg} / \mathrm{dl})]+1.875 \mathrm{x} \log$ [international normalized ratio (INR)] $+0.667 \mathrm{x}$ (growth failure height or weight $\geq 2$-SD below the age- and sex-adjusted mean) (27). The Bayley Scales of Infant Development (BSID) is a standardized technique and measurement tool for evaluating the psychomotor behaviors of children aged between 2 months and 3 years (28). BSID revised by the Hunan Medical University in 1990 was used to assess the psychomotor and behavior development conditions of all of the infants (29). According to the raw score, the corresponding mental development index (MDI) and psychomotor development index (PDI) were calculated to analyze the effect of liver transplantation on the neurocognitive behaviors of infants. All examinations were carried out in a quiet environment. The MDI and PDI are standard scores obtained from the conversion table based on the corresponding raw score of age and other values. The average number is 100 and the standard deviation is $16 ;>90$ points indicated a normal level and $<90$ indicated poor development. Furthermore, the postoperative delirium of infants was independently evaluated by two physicians at $30 \mathrm{~min}, 2$ and $4 \mathrm{~h}$ following extubation using the pediatric anesthesia emergence delirium (PAED) scale (30).

Statistical analysis. Statistical analyses were performed using SPSS software (version 20.0; IBM Corp.). Continuous data were tested with the Kolmogorov-Smirnov test and are presented as mean \pm SD or medians (first and third quartiles), 
as appropriate. Data were analyzed using repeated-measures ANOVA with the Bonferroni post-hoc test across different time points. Categorical data are presented as $\mathrm{n}(\%)$ and were compared with the $\chi^{2}$ test or Fisher's exact test with the Bonferroni post-hoc test, as appropriate. Pearson's correlation analysis was used to analyze the correlation between NSE and $\mathrm{S}-100 \beta$ at T3, PAED scores at $30 \mathrm{~min}$ and MDI and PDI at 1 month following surgery. $\mathrm{P}<0.05$ was considered to indicate a statistically significant difference.

\section{Results}

Characteristics of the transplantations. Parental donor piggyback liver transplantations were performed. The left lateral lobe of the donor liver was used for transplantation, with a graft-to-recipient weight ratio of $0.83-5.16 \%$. The mean operation time was $8.2 \pm 1.2 \mathrm{~h}$. The mean anhepatic phase was $45.5 \pm 12.4 \mathrm{~min}$. The median cold ischemia time of the donor livers was $95(64,178) \mathrm{min}$. The infusion of red blood cells was $2.00(2.00,3.68)$ units. The infusion of plasma was 400 $(210,400) \mathrm{ml}$. Data are presented in Table I.

Significant hemodynamic changes observed during surgery. The anhepatic and hepato-reperfusion phases (T2 and T3) MAP and CVP decreased significantly compared with T1 and T2 ( $<<0.05$ at all time points). MAP and CVP gradually recovered during the hepato-reperfusion phase (Table II).

NSE and S100 $\beta$ levels are elevated during and following transplantation. Levels of NSE and S100 $\beta$ were increased significantly at T2, T3 and T4 compared with $\mathrm{T} 1 \quad(\mathrm{P}<0.05)$ (Table II). Levels gradually increased at T2 and peaked at T3 compared with T1 $(\mathrm{P}<0.05)$. Furthermore, S-100 $\beta$ and NSE levels decreased gradually at $\mathrm{T} 4$ compared with $\mathrm{T} 3(\mathrm{P}<0.05)$. These results indicated that liver transplantation caused a certain degree of brain injury.

Rate of delirium is high following extubation and decreases with time. The rate of delirium was $17.4 \%$ at 30 min post-extubation (Table III). The incidence of delirium was significantly lower at $2 \mathrm{~h}(6.9 \%)$ and $4 \mathrm{~h}(3.4 \%)$ post-extubation ( $\mathrm{P}<0.05 \mathrm{vs}$. 30 min post-extubation) The PAED score was $9.6 \pm 2.4$ at $30 \mathrm{~min}$ post-extubation (Table III). The PAED score was significantly lower at $2 \mathrm{~h}(6.6 \pm 1.8)$ and $4 \mathrm{~h}(4.0 \pm 1.1)$ post-extubation $(\mathrm{P}<0.05$ vs. $30 \mathrm{~min}$ post-extubation).

A certain degree of brain injury occurs during liver transplantation. MDI and PDI were decreased at 3 months after surgery compared with 1 day prior to surgery (MDI, 87.7 \pm 8.4 vs. $84.5 \pm 8.5, \mathrm{P}=0.015$; $\mathrm{PDI}, 82.9 \pm 8.7$ vs. $79.6 \pm 8.8, \mathrm{P}=0.016$; Table IV). These results indicated that a certain degree of brain injury occurred in the infants during or following liver transplantation.

Brain injury markers are correlated with the developmental indexes. NSE and S-100 $\beta$ (T3) were linearly correlated with MDI and PDI 3 months after surgery. NSE was moderate negatively correlated with postoperative $\mathrm{MDI}(\mathrm{r}=-0.367 ; \mathrm{P}=0.001$; Fig. 1A) and PDI (r=-0.441; $\mathrm{P}<0.001$; Fig. 1B). Furthermore, $\mathrm{S}-100 \beta$ was weakly negatively correlated with MDI $(r=-0.254$;
Table I. Patient characteristics and operation indicators.

\begin{tabular}{|c|c|}
\hline Variables & Values \\
\hline Age, months & $8.1(6.6,10.2)$ \\
\hline \multicolumn{2}{|l|}{ Sex } \\
\hline Male & $51(59.3 \%)$ \\
\hline Female & $35(40.7 \%)$ \\
\hline Weight, kg & $7.6 \pm 1.7$ \\
\hline Height, cm & $66.3 \pm 7.2$ \\
\hline \multicolumn{2}{|l|}{ ASA status } \\
\hline III & $62(72.1 \%)$ \\
\hline IV & $24(27.9 \%)$ \\
\hline PELD score & $16.6 \pm 2.2$ \\
\hline Preoperative serum creatinine, $\mu \mathrm{mol} / \mathrm{l}$ & $17.34 \pm 4.68$ \\
\hline Preoperative ALT, U/l & $114.46 \pm 48.25$ \\
\hline Preoperative AST, U/l & $206.80 \pm 85.26$ \\
\hline$\gamma$-glutaryl transferase, $\mathrm{U} / \mathrm{l}$ & $435.8 \pm 95.66$ \\
\hline Total bilirubin, mg/dl & $205.42 \pm 90.48$ \\
\hline Anhepatic time, min & $45.5 \pm 12.4$ \\
\hline Operation time, $\mathrm{h}$ & $8.2 \pm 1.2$ \\
\hline Anesthesia duration, $\mathrm{h}$ & $10.1 \pm 1.3$ \\
\hline Bleeding volume, $\mathrm{ml}$ & $127 \pm 30$ \\
\hline Urine volume, $\mathrm{ml}$ & $424 \pm 62$ \\
\hline Intraoperative blood transfusions, units & $2.0(2.0,3.7)$ \\
\hline Intraoperative frozen plasma transfusions, $\mathrm{ml}$ & $400(210,400)$ \\
\hline Graft cold ischemia time, min & $95(64,178)$ \\
\hline
\end{tabular}

ASA, American Society of Anesthesiologists; PELD, pediatric end-stage liver disease; ALT, alanine aminotransferase; AST, aspartate aminotransferase.

$\mathrm{P}=0.018$; Fig. $1 \mathrm{C})$ and moderate negatively with $\mathrm{PDI}(\mathrm{r}=-0.312$; $\mathrm{P}=0.003$ Fig. 1D). NSE was weak correlated with PAED 30 min after surgery $(\mathrm{r}=0.251 ; \mathrm{P}=0.020 ;$ Fig. $2 \mathrm{~A})$. These results indicated that $\mathrm{S}-100 \beta$ was not correlated with PAED $30 \mathrm{~min}$ $(\mathrm{r}=0.004 ; \mathrm{P}=0.970$; Fig. 2B), 2 h ( $\mathrm{r}=0.067$; $\mathrm{P}=0.543$; Fig. 2D) and $4 \mathrm{~h}(\mathrm{r}=0.060 ; \mathrm{P}=0.581 ; \mathrm{Fig} .2 \mathrm{~F})$ after surgery. NSE was not correlated with PAED 2 ( $\mathrm{r}=0.197 ; \mathrm{P}=0.069$; Fig. 2C) and $4 \mathrm{~h}$ $(\mathrm{r}=0.141 ; \mathrm{P}=0.194$; Fig. $2 \mathrm{E})$ after surgery, and also the elevated markers of neurological injury during or after surgery may be correlated with delayed development.

\section{Discussion}

The present study evaluated the effect of liver transplantation on the brains of infants according to the perioperative serum brain injury markers S-100 $\beta$ and NSE. The results indicated that hemodynamic fluctuations were significant during the anhepatic and hepato-reperfusion phases (T2-T4). The levels of brain injury markers S-100 $\beta$ and NSE increased and peaked at the ischemia-reperfusion phase (T3), indicating that ischemia-reperfusion may affect the brains of the pediatric patients to a certain degree. In addition, the incidence of delirium was highest at $30 \mathrm{~min}$ post-extubation. MDI and PDI 
Table II. Changes in hemodynamics, serum $\mathrm{pH}$ and biomarkers.

\begin{tabular}{lcrrr}
\hline Variable & T1 & \multicolumn{1}{c}{ T2 } & T3 & T4 \\
\hline $\mathrm{HR}$, beat/min & $118.42 \pm 12.25$ & $132.25 \pm 14.55^{\mathrm{a}}$ & $112.18 \pm 10.12^{\mathrm{a}, \mathrm{b}}$ & $105.28 \pm 7.16^{\mathrm{a}-\mathrm{c}}$ \\
$\mathrm{MAP}, \mathrm{mmHg}$ & $46.23 \pm 7.18$ & $40.35 \pm 8.16^{\mathrm{a}}$ & $49.25 \pm 7.36^{\mathrm{a}, \mathrm{b}}$ & $53.62 \pm 3.28^{\mathrm{a}-\mathrm{c}}$ \\
$\mathrm{CVP}, \mathrm{cmH}_{2} \mathrm{O}$ & $4.36 \pm 1.42$ & $2.84 \pm 1.06^{\mathrm{a}}$ & $6.42 \pm 1.91^{\mathrm{a}, \mathrm{b}}$ & $7.42 \pm 2.23^{\mathrm{a}-\mathrm{c}}$ \\
$\mathrm{pH}$ & $7.45 \pm 0.46$ & $7.32 \pm 0.44^{\mathrm{a}}$ & $7.39 \pm 0.65^{\mathrm{a}, \mathrm{b}}$ & $7.42 \pm 0.51^{\mathrm{b}, \mathrm{c}}$ \\
$\mathrm{NSE}, \mathrm{ng} / \mathrm{ml}$ & $23.46 \pm 3.74$ & $28.85 \pm 4.14^{\mathrm{a}}$ & $35.57 \pm 7.06^{\mathrm{a}, \mathrm{b}}$ & $29.25 \pm 4.90^{\mathrm{a}, \mathrm{c}}$ \\
$\mathrm{S} 100-\beta(\mathrm{ng} / \mathrm{ml})$ & $3.97 \pm 0.79$ & $7.69 \pm 1.92^{\mathrm{a}}$ & $12.36 \pm 3.29^{\mathrm{a}, \mathrm{b}}$ & $6.87 \pm 2.11^{\mathrm{a}, \mathrm{c}}$ \\
\end{tabular}

${ }^{\mathrm{a}} \mathrm{P}<0.05$ vs. T1; ${ }^{\mathrm{b}}<0.05$ vs. T2; ${ }^{\mathrm{C}} \mathrm{P}<0.05$ vs. T3. T1, the time following anesthesia; $\mathrm{T} 2,30 \mathrm{~min}$ after the anhepatic phase; $\mathrm{T} 3,1 \mathrm{~h}$ after the neohepatic phase; T4, $24 \mathrm{~h}$ after the neohepatic phase. HR, heat rate; MAP, mean arterial pressure; CVP, central venous pressure; NSE, neuron-specific enolase; S100- $\beta$, serum calcium-binding protein $\beta$.

Table III. Comparison of delirium values following extubation.

\begin{tabular}{lccc}
\hline Indicator & 30 min post-extubation & 2 h post-extubation & 4 h post-extubation \\
\hline PAED score & $9.6 \pm 2.4$ & $6.6 \pm 1.8^{\mathrm{a}}$ & $4.0 \pm 1.1^{\mathrm{a}}$ \\
Rate of delirium & $15(17.4 \%)$ & $6(6.9 \%)^{\mathrm{a}}$ & $3(3.4 \%)^{\mathrm{a}}$ \\
\hline
\end{tabular}

${ }^{a} \mathrm{P}<0.05$ vs. 30 min post-extubation. PAED, pediatric anesthesia emergence delirium.

Table IV. Changes in MDI and PDI prior to and after liver transplantation.

\begin{tabular}{lccc}
\hline Indicator & $\begin{array}{l}\text { 1 day prior } \\
\text { to surgery }\end{array}$ & $\begin{array}{c}3 \text { months } \\
\text { after surgery }\end{array}$ & P-value \\
\hline MDI & $87.7 \pm 8.4$ & $84.5 \pm 8.5$ & 0.015 \\
PDI & $82.9 \pm 8.7$ & $79.6 \pm 8.8$ & 0.016
\end{tabular}

MDI, mental development index; PDI, psychomotor development index.

were decreased at 3 months after surgery compared with 1 day prior to surgery. Furthermore, S-100 $\beta$ and NSE were negatively correlated with MDI and PDI, indicating that elevated markers of neurological injury during or after surgery may be correlated with delayed brain development. These results strongly suggested that there was a certain degree of brain injury following liver transplantation in children with biliary atresia.

Currently, it is hypothesized that multiple factors are involved in perioperative brain injury during liver transplantation. The suggested pathogenesis is that intraoperative liver ischemia/reperfusion leads to the impaired autoregulation of cerebral blood flow, and intraoperative hemorrhage, infusion and inferior vena cava blockage, which may cause significant hemodynamic changes, and result in drastic fluctuation of cerebral blood perfusion and oxygenation, particularly at the neohepatic phase $(31,32)$. Furthermore, the release of inflammatory factors induced by liver transplantation may result in large amounts of oxygen-free radicals, which may lead to cerebral edema, delayed neuronal death and other serious injuries $(31,32)$.

$\mathrm{S}-100 \beta$ is a nervous tissue protein with high concentrations in the brain (18). Following necrosis of nerve cells, $\mathrm{S}-100 \beta$ is released into the cerebrospinal fluid and enters the bloodstream through the damaged blood-brain barrier (18-20). The levels of S-100 $\beta$ in body fluids have been used to monitor perinatal asphyxia in infants and to guide clinical treatment (16). NSE is mainly present in neurons and neurosecretory cells, and is an important marker of brain injury $(20,21)$. The physical and chemical properties of NSE are quite stable and changes in the external environments have little effect on levels (23). NSE is closely associated with neuronal injury and can be used as an important parameter to assess the severity of neuronal injury (23). High postoperative levels of S-100 $\beta$ and NSE are well known to be associated with brain injury in pediatric patients who have undergone major surgeries $(24,25)$. However, to the best of our knowledge, the changes in S-100 $\beta$ and NSE levels in pediatric patients with biliary atresia undergoing parental donor liver transplantation remains unknown. The current study demonstrated that the serum levels of S-100 $\beta$ and NSE in infants undergoing liver transplantation after induction of anesthesia were significantly higher compared with normal preoperative values. The possible underlying mechanism was that preoperative abnormal liver function and liver failure led to the disturbance of electrolyte levels and the acid-base equilibrium, metabolic disorders. Preoperative brain functions in patients with end-stage diseases are usually manifested as serious abnormal infections (17). Additionally, biliary atresia can result in ischemia, sepsis, acid-base imbalance and electrolyte disturbance, which can cause different degrees of damage to the central nervous system (17). 

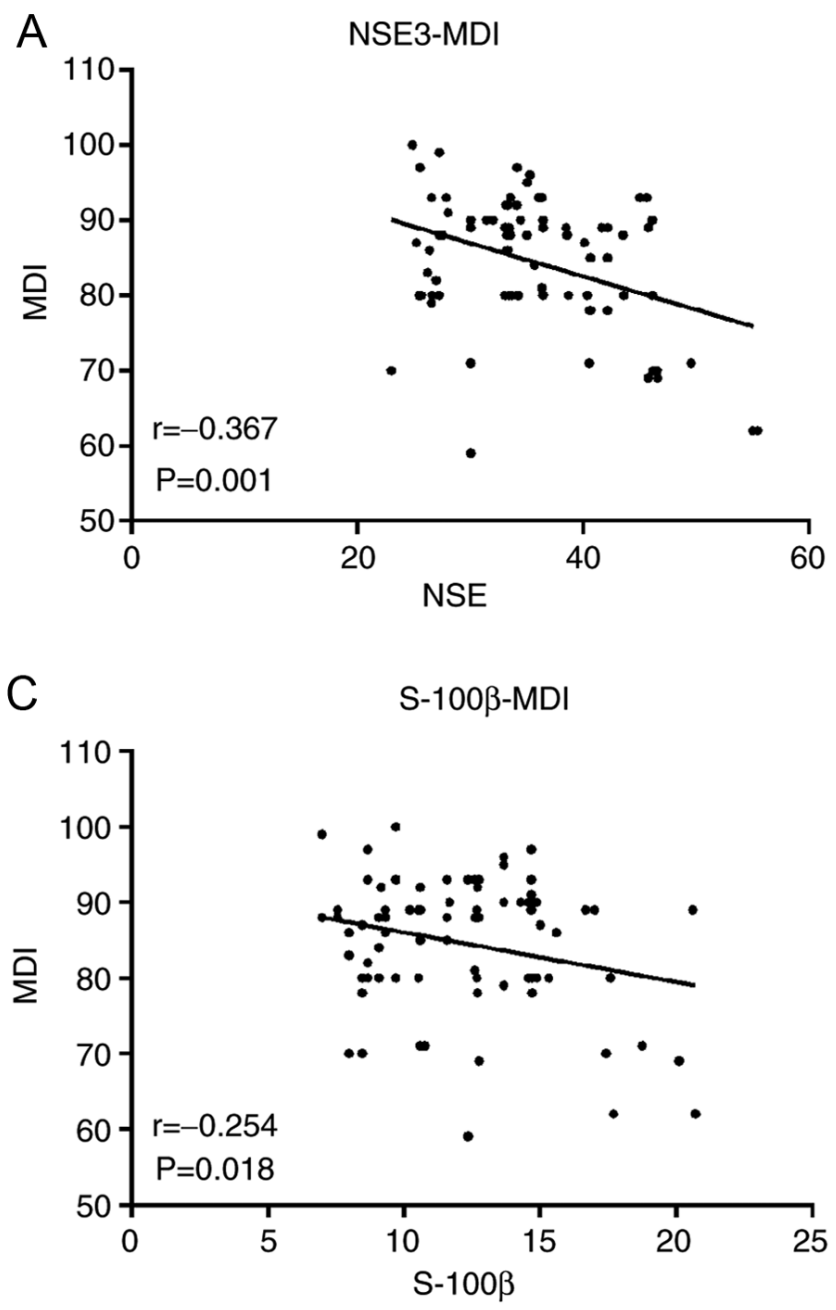

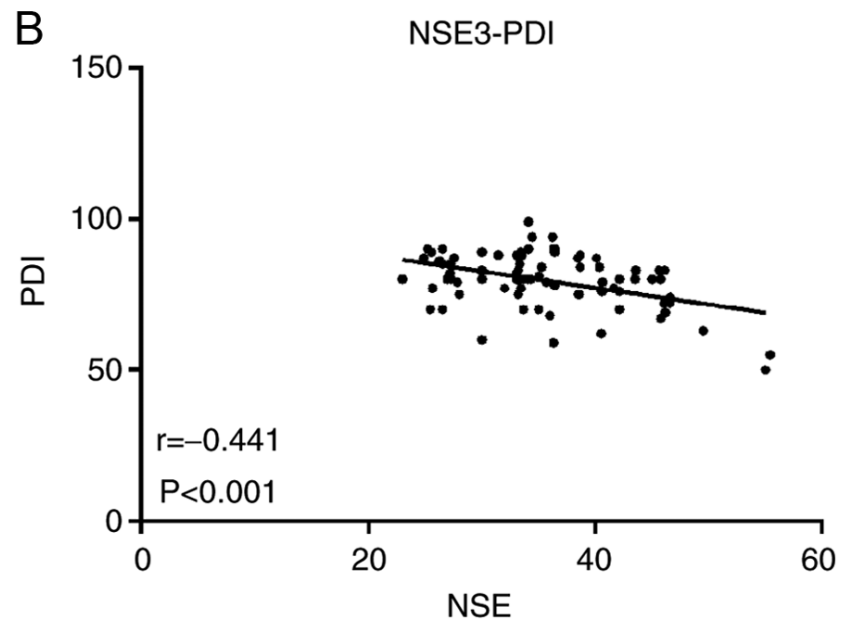

D S-100ß-PDI

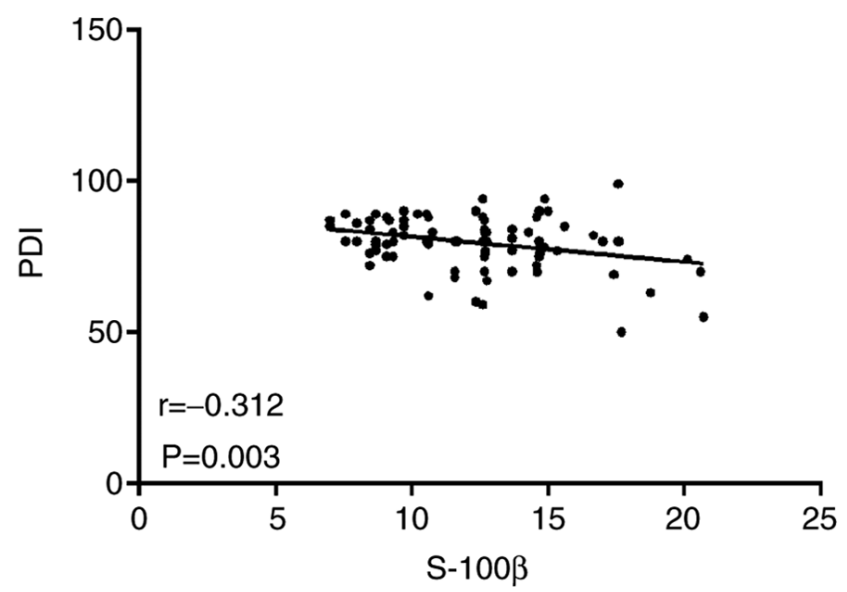

Figure 1. Correlation analysis between NSE and S-100 $\beta$ with MDI and PDI 3 months after surgery (T3). (A) Correlation between NSE and MDI. (B) Correlation between NSE and PDI. (C) Correlation between S-100 $\beta$ and MDI. (D) Correlation between S-100 $\beta$ and PDI. NSE, neuron-specific enolase; S100- $\beta$, serum calcium-binding protein $\beta$; MDI, mental development index; PDI, psychomotor development index.

Parental donor liver transplantation is complicated. In all donor transplants, when anastomosing the inferior vena cava and donor hepatic vein, the inferior vena cava needs to be blocked (33). After entering the anhepatic phase, HR is increased, MAP and CVP are decreased and tissue hypoperfusion and hypoxic metabolism produce a numerous acidic metabolites. Ultimately, S-100 $\beta$ and NSE levels are increased and peak following liver transplantation and reperfusion. Cardiac output does not recover rapidly in the early neohepatic phase $(31,32)$; instead, it is decreased further, and numerous acidic metabolites, endotoxins, vasoactive substances and inflammatory factors can cause damage to the nervous system in the early stage $(31,32)$. If liver transplantation is successful, the new liver can gradually recover these imbalances and there is a gradual reducing trend in the aforementioned products following surgery.

The use of elevated serological indicators for the assessment of brain injury is uncertain; therefore, the present study further investigated neurobehavioral cognition and postoperative delirium in infants. BSID is a standardized technique and measurement tool used to evaluate the psychomotor behaviors of children aged between 2 months and 3 years, and can be used to evaluate the sensitivity, discriminability and ability to respond to external factors of sensory perception, learning and memorizing and psychomotor abilities (28). In the present study, BSID was applied to evaluate the psychomotor behavior conditions of infants prior to and following liver transplantation. The preoperative MDI and PDI scores were significantly lower compared with normal levels (data not shown), indicating that there was a certain neurocognitive dysfunction in infants with biliary atresia. The MDI and PDI scores at 3 months after liver transplantation were lower compared with those prior to surgery. The postoperative delirium conditions indicated that the incidence of delirium was higher in a short time period (30 min) following extubation, which strongly suggested that liver transplantation may cause a certain degree of brain injury in infants. Furthermore, the MDI and PDI scores from the correlation analysis were consistent with the results for S-100 $\beta$ and NSE levels.

NSE and S-100 $\beta$ are well-known markers of brain injury (18-23). High postoperative levels of S-100 $\beta$ and NSE have been reported to be associated with brain injury in pediatric patients who have undergone major surgeries $(24,25)$. However, to the best of our knowledge, the perioperative changes in S-100 $\beta$ and NSE levels in pediatric patients with ESLD undergoing parental donor liver transplantation is 
A

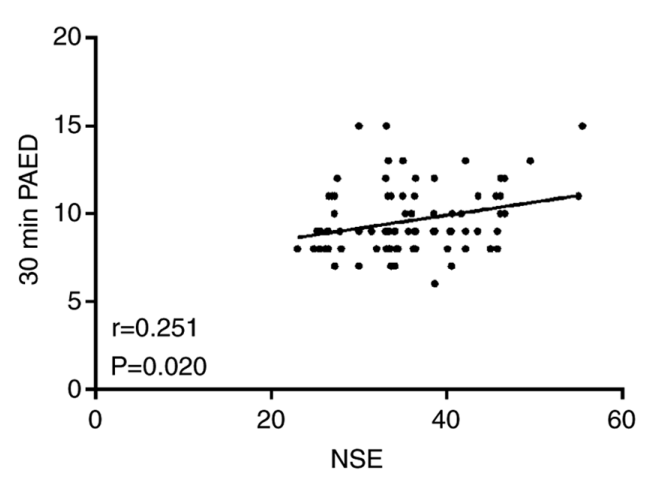

C

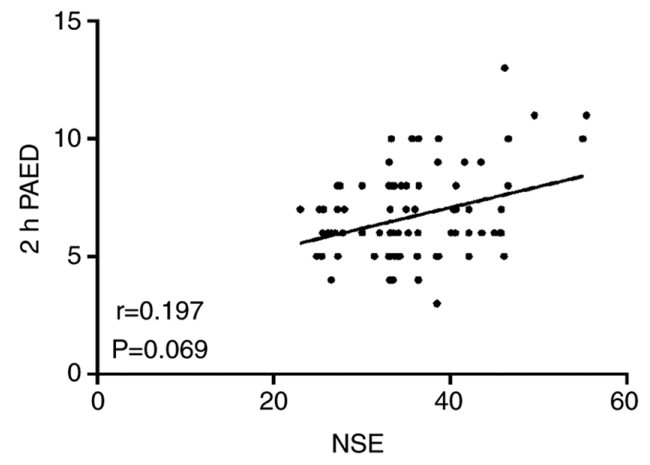

$E$

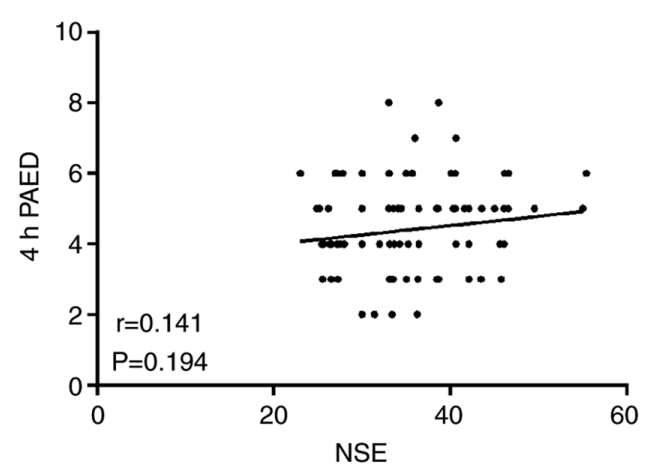

B S-100ß-PAED $30 \mathrm{~min}$

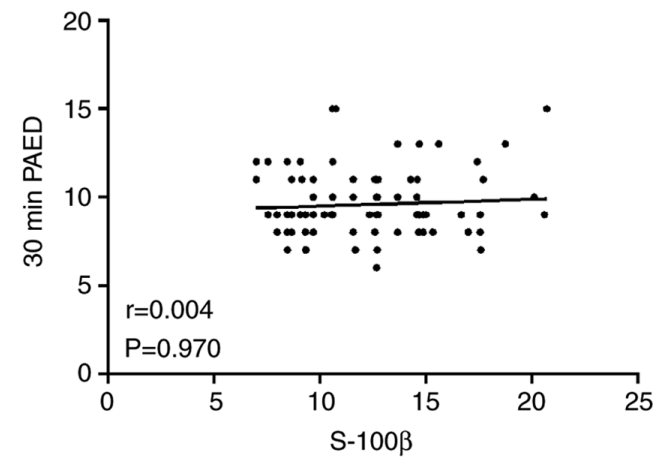

D

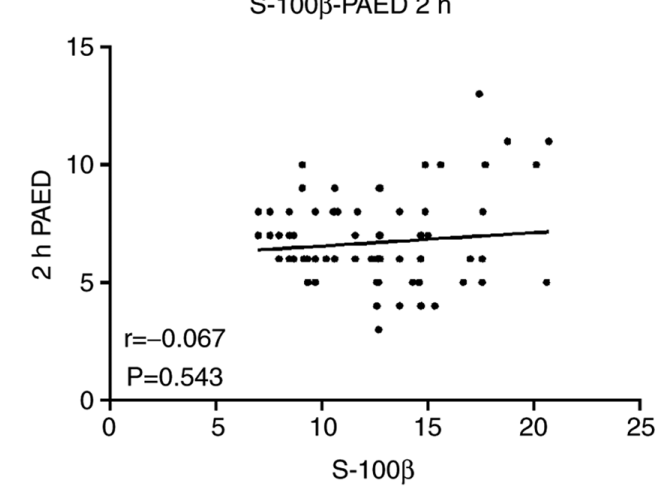

$\mathrm{F}$

S-100ß-PAED $4 \mathrm{~h}$

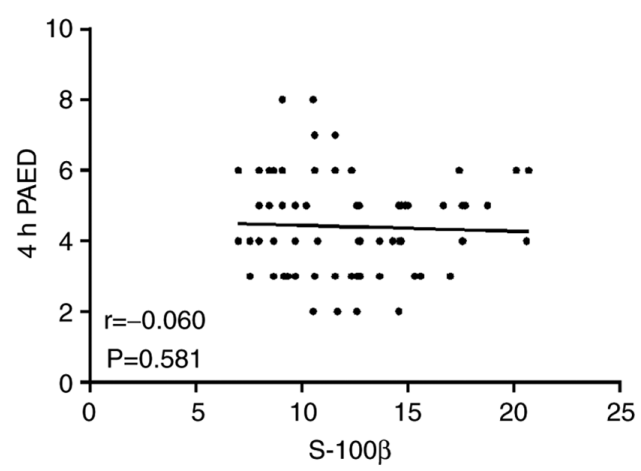

Figure 2. Correlation analysis of NSE and S-100 $\beta$ with PAED. (A) Correlation between NSE and PAED 30 min after surgery. (B) Correlation between S-100 $\beta$ and PAED $30 \mathrm{~min}$ after surgery. (C) Correlation between NSE and PAED $2 \mathrm{~h}$ after surgery. (D) Correlation between S-100 $\beta$ and PAED $2 \mathrm{~h}$ after surgery. (E) Correlation between NSE and PAED $4 \mathrm{~h}$ after surgery. (F) Correlation between S-100 $\beta$ and PAED $4 \mathrm{~h}$ after surgery. NSE, neuron-specific enolase; S100- $\beta$, serum calcium-binding protein $\beta$; PAED, pediatric anesthesia emergence delirium.

unknown. The present study indicated that pediatric patients with ESLD undergoing parental donor liver transplantation suffered from brain injury. The elevation of S-100 $\beta$ and NSE peaked at $1 \mathrm{~h}$ in the neohepatic phase. This may indicate the timing of brain protection methods in these pediatric patients. This result indicated that timely and effective brain protection measures, taken during the 1st hour of the neohepatic phase, may decrease the level of S-100 $\beta$ and NSE

The present study had limitations. Firstly, it was a single-center study and only included infants with simple biliary atresia undergoing parental donor liver transplantation. Only two markers of brain injury and hemodynamics were assessed, and systemic inflammation and oxidative stress were not measured. Additionally, blood samples were available only for the four time points examined, and multiple samples for the dynamic assessment of NSE and S-100 $\beta$ were not available. Therefore, multicenter studies involving more samples are required to determine the association of NSE and S-100 $\beta$ with brain injury.

In conclusion, brain injury was observed in the perioperative period in pediatric patients during parental donor liver transplantation, as indicated by elevated serum NSE and $\mathrm{S}-100 \beta$ levels. The anhepatic phase and ischemia-reperfusion caused a certain degree of brain injury. NSE and S-100 $\beta$ levels were also correlated with infant development scores. The detection of perioperative brain injury markers may be used to determine and predict postoperative brain injury, thus providing guidance for clinical cerebral protection. Clinical 
cerebral protection is important for the prevention of postoperative neurological complications in infants following parental donor liver transplantation.

\section{Acknowledgements}

Not applicable.

\section{Funding}

The present study was supported by the 2018 Tianjin Natural Science Foundation Project (grant no. 2016N0039KY), the Tianjin Clinical Key Discipline Project (Anesthesiology; grant no. NCT03024840), the College Program of Tianjin First Central Hospital (grant no. CF201819), the Tianjin Health and Family Planning Commission of Science and Technology Research Projects (grant no. 16KG101), the Tianjin Health and Family Planning Commission of Chinese and Western Medicine of Traditional Chinese Medicine Combined with Scientific Research Subject (grant no. 2017056) and the 2017 Tianjin Natural Science Fund Project (grant no. 17JCYBJC28000). The funding bodies had no role in the design of the present study or the collection, analysis, data interpretation or the writing of the manuscript.

\section{Availability of data and materials}

The datasets used and/or analyzed during the current study are available from the corresponding author on reasonable request.

\section{Authors' contributions}

WY and HY conceptualized the study. YSh contributed to the design of the present study. GZ and YSu contributed to performing the experiments, acquiring results and the analysis. MZ interpreted the data. HY drafted and substantially revised the manuscript. All authors read and approved the final manuscript.

\section{Ethics approval and consent to participate}

The present study was approved by the Medical Ethics Committee of Tianjin First Central Hospital, Tianjin, China (approval no. 2016N0039KY) and written informed consent was obtained from the infants' parents or guardians. The privacy rights of human subjects were observed.

\section{Patient consent for publication}

Not applicable.

\section{Competing interests}

The authors declare that they have no competing interests.

\section{References}

1. Sokal EM, Goldstein D, Ciocca M, Lewindon P, Ni YH, Silveira T, Sibal A, Dhawan A, Mack C and Bucuvalas J; End-Stage Liver Disease Working Group: End-stage liver disease and liver transplant: Current situation and key issues. J Pediatr Gastroenterol Nutr 47: 239-246, 2008.
2. Protheroe SM and Kelly DA: Cholestasis and end-stage liver disease. Baillieres Clin Gastroenterol 12: 823-841, 1998.

3. Group SR: Studies of Pediatric Liver Transplantation (SPLIT): Year 2000 outcomes. Transplantation 72: 463-476, 2001.

4. Young S, Kwarta E, Azzam R and Sentongo T: Nutrition assessment and support in children with end-stage liver disease. Nutr Clin Pract 28: 317-329, 2013.

5. Stanescu AL, Hryhorczuk AL, Chang PT, Lee EY and Phillips GS: Pediatric abdominal organ transplantation: Current indications, techniques, and imaging findings. Radiol Clin North Am 54: 281-302, 2016.

6. Tannuri AC, Gibelli NE, Ricardi LR, Silva MM, Santos MM, Pinho-Apezzato ML, Maksoud-Filho JG, Velhote MC, Ayoub AA, Andrade WC, et al: Orthotopic liver transplantation in biliary atresia: A single-center experience. Transplant Proc 43: 181-183, 2011.

7. Colledan M, Torri E, Bertani A, Corno V, Guizzetti M, Lucianetti A, Maldini G, Pinelli D, Zambelli M, Giovanelli M, et al: Orthotopic liver transplantation for biliary atresia. Transplant Proc 37: 1153-1154, 2005.

8. Ameres M, Melter M, Zant R, Schilling S and Geis T: Liver transplantation during infancy: No increased rate of neurological complications. Pediatr Transplant 22: e13304, 2018.

9. Menegaux F, Keeffe EB, Andrews BT, Egawa H, Monge H, Concepcion W, So SK and Esquivel CO: Neurological complications of liver transplantation in adult versus pediatric patients. Transplantation 58: 447-450, 1994.

10. Nemati H, Kazemi K and Mokarram AT: Neurological complications associated with pediatric liver transplant in Namazi hospital: One-year follow-up. Int J Organ Transplant Med 10: 30-35, 2019.

11. Squires RH, Ng V, Romero R, Ekong U, Hardikar W, Emre S and Mazariegos GV: Evaluation of the pediatric patient for liver transplantation: 2014 practice guideline by the American Association for the Study of Liver Diseases, American Society of Transplantation and the North American Society for Pediatric Gastroenterology, Hepatology and Nutrition. Hepatology 60: 362-398, 2014.

12. Schifilliti D, Mondello S, D'Arrigo MG, Chille G and Fodale V: Genotoxic effects of anesthetic agents: An update. Expert Opin Drug Saf 10: 891-899, 2011

13. Istaphanous $\mathrm{G}$ and Loepke $\mathrm{AW}$ : General anesthetics and the developing brain. Curr Opin Anaesthesiol 22: 368-373, 2009.

14. Vutskits L: Anesthetic-related neurotoxicity and the developing brain: Shall we change practice? Paediatr Drugs 14: 13-21, 2012.

15. Stratmann G: Review article: Neurotoxicity of anesthetic drugs in the developing brain. Anesth Analg 113: 1170-1179, 2011.

16. Wainwright MS, Craft JM, Griffin WS, Marks A, Pineda J,Padgett KR and Van Eldik LJ: Increased susceptibility of S100B transgenic mice to perinatal Hypoxia-ischemia. Ann Neurol 56: 61-67, 2004.

17. Chiaretti A, Barone G, Riccardi R, Antonelli A, Pezzotti P, Genovese O, Tortorolo L and Conti G: NGF, DCX, and NSE upregulation correlates with severity and outcome of head trauma in children. Neurology 72: 609-616, 2009.

18. Egea-Guerrero JJ, Revuelto-Rey J, Murillo-Cabezas F, Muñoz-Sánchez MA, Vilches-Arenas A, Sánchez-Linares P, Domínguez-Roldán JM and León-Carrión J: Accuracy of the S100 $\beta$ protein as a marker of brain damage in traumatic brain injury. Brain Inj 26: 76-82, 2012.

19. Yao B, Zhang LN, Ai YH, Liu ZY and Huang L: Serum $\mathrm{S} 100 \beta$ is a better biomarker than neuron-specific enolase for Sepsis-associated encephalopathy and determining its prognosis: A prospective and observational study. Neurochem Res 39: 1263-1269, 2014

20. Oris C, Pereira B, Durif J, Simon-Pimmel J, Castellani C, Manzano S, Sapin V and Bouvier D: The Biomarker S100B and Mild Traumatic Brain Injury: A Meta-analysis. Pediatrics 141: e20180037, 2018.

21. Thelin EP, Jeppsson E, Frostell A, Svensson M, Mondello S, Bellander BM and Nelson DW: Utility of neuron-specific enolase in traumatic brain injury; relations to S100B levels, outcome, and extracranial injury severity. Crit Care 20: 285, 2016.

22. Rech TH, Vieira SR, Nagel F, Brauner JS and Scalco R: Serum neuron-specific enolase as early predictor of outcome after in-hospital cardiac arrest: A cohort study. Crit Care 10: R133, 2006.

23. Nakhjavan-Shahraki B, Yousefifard M, Oraii A, Sarveazad A and Hosseini M: Meta-analysis of neuron specific enolase in predicting pediatric brain injury outcomes. EXCLI J 16: 995-1008, 2017. 
24. Schmitt B, Bauersfeld U, Schmid ER, Tuchschmid P, Molinari L, Fanconi $S$ and Bandtlow C: Serum and CSF levels of neuron-specific enolase (NSE) in cardiac surgery with cardiopulmonary bypass: A marker of brain injury? Brain Dev 20: 536-539, 1998.

25. Liu Y, Xu Y, Li DZ, Shi Y and Ye M: Comparison of S100B and NSE between cardiac surgery and interventional therapy for children. Pediatr Cardiol 30: 893-897, 2009.

26. Saklad M: Grading of patients for surgical procedures. Anesthesiology 2: 281-284, 1941

27. Freeman RB Jr, Wiesner RH, Roberts JP, McDiarmid S, Dykstra DM and Merion RM: Improving liver allocation: MELD and PELD. Am J Transplant 4 (Suppl 9): S114-S131, 2004.

28. Bayley N: Bayley scales of infant development. 2nd edition. Psychological Corporation, San Antonio, 1993.

29. Bai Y, Shang G, Wang L, Sun Y, Osborn A and Rozelle S: The relationship between birth season and early childhood development: Evidence from northwest rural China. PLoS One 13: e0205281, 2018.
30. Sikich N and Lerman J: Development and psychometric evaluation of the pediatric anesthesia emergence delirium scale. Anesthesiology 100: 1138-1145, 2004.

31. Weiss $\mathrm{N}$ and Thabut D: Neurological complications occurring after liver transplantation: Role of risk factors, hepatic encephalopathy, and acute (on Chronic) brain injury. Liver Transpl 25: 469-487, 2019.

32. Singh S, Nasa V and Tandon M: Perioperative monitoring in liver transplant patients. J Clin Exp Hepatol 2: 271-278, 2012.

33. Cuenca AG, Kim HB and Vakili K: Pediatric liver transplantation. Semin Pediatr Surg 26: 217-223, 2017.

This work is licensed under a Creative Commons Attribution-NonCommercial-NoDerivatives 4.0 International (CC BY-NC-ND 4.0) License. 